07.2;07.3

\title{
Импульсные характеристики кремниевых фотоэлектрических преобразователей, облученных низкоэнергетическими протонами
}

\author{
() Н.М. Богатов ${ }^{1}$, Л.Р. Григорьян ${ }^{1}$, А.И. Коваленко ${ }^{1}$, М.С. Коваленко ${ }^{1}$, Л.С. Лунин ${ }^{2}$ \\ ${ }^{1}$ Кубанский государственный университет, Краснодар, Россия \\ ${ }^{2}$ Федеральный исследовательский центр Южный научный центр РАН, Ростов-на-Дону, Россия \\ E-mail: bogatov@phys.kubsu.ru, bogatov.n@inbox.ru
}

Поступило в Редакцию 23 октября 2020 г.

В окончательной редакции 17 декабря 2020 г.

Принято к публикации 17 декабря 2020г.

\begin{abstract}
Исследовано влияние облучения низкоэнергетическими протонами на импульсные характеристики кремниевых фотоэлектрических структур. Для измерения использовались биполярные прямоугольные импульсы напряжения с постоянной амплитудой $10 \mathrm{mV}$ и частотой $200 \mathrm{kHz}$ и $1 \mathrm{MHz}$. Показано, что облучение протонами с энергией $180 \mathrm{keV}$ и дозой $10^{15} \mathrm{~cm}^{-2}$ создает в области пространственного заряда $n^{+}-p$ перехода область с высокой концентрацией радиационных дефектов. Такие элементы могут использоваться для создания быстродействующих фотодиодов с рабочей частотой модуляции $18 \mathrm{MHz}$.
\end{abstract}

Ключевые слова: фотодиод, кремний, время жизни, протон.

DOI: 10.21883/PJTF.2021.07.50791.18596

Импульсные характеристики фотодиодов зависят от рекомбинационных параметров полупроводниковых структур. В кремнии время жизни неравновесных носителей заряда определяется рекомбинацией через примесные центры. Облучение кремниевых структур протонами дает возможность уменьшить время жизни носителей заряда в локальном объеме структуры, что позволяет улучшить совокупность статических и частотных характеристик приборов [1].

Измерения времени жизни неосновных носителей заряда с помощью регистрируемой микроволновым излучением фотопроводимости используются для контроля результатов технологических воздействий [2]. На значение времени жизни, измеренное по изменению фотопроводимости, влияет поверхностная рекомбинация $[3,4]$. Влияние структурных дефектов на объемную составляющую времени жизни неосновных носителей заряда и скорости рекомбинации в $p-n$-переходе в двустороннем солнечном элементе на основе поликристаллического кремния определялось исходя из экспериментальной кривой переходного напряжения при импульсном освещении [5].

Низкоэнергетические протоны создают радиационные дефекты с максимумом распределения в области пика Брэгга, расположение которого в объеме облучаемого образца определяется энергией падающих протонов. В работах $[6,7]$ исследовано влияние протонов с энергией $E_{p}=40$ и $180 \mathrm{keV}$ при температуре облучаемых образцов $T_{p}=83$ и $300 \mathrm{~K}$ на параметры вольт-амперных характеристик кремниевых фотоэлектрических преобразователей (ФЭП) $n^{+}-p-p^{+}$-типа. Показано, что протоны с начальной энергией $40 \mathrm{keV}$ преимущественно изменяют физические свойства $n^{+}$-слоя, а протоны с начальной энергией $180 \mathrm{keV}$ - свойства области пространственного заряда (ОПЗ) в р-слое. Количество радиационных дефектов в максимуме распределения в $n^{+}$-слое при $E_{p}=40 \mathrm{keV}, T_{p}=83 \mathrm{~K}$ много меньше, чем в $p$-слое при $E_{p}=180 \mathrm{keV}, T_{p}=83 \mathrm{~K}$ и в $n^{+}$-слое при $E_{p}=40 \mathrm{keV}, T_{p}=300 \mathrm{~K}$. Импульсные характеристики облученных структур в этих работах не исследовались.

Цель настоящей работы - изучение влияния облучения низкоэнергетическими протонами на импульсные характеристики кремниевых структур с диффузионным $n^{+}-p$-переходом. Чтобы исключить временну́ю зависимость фототока и фотопроводимости в методиках [2-5], измерялось переходное напряжение в неосвещенных образцах.

Исследовались фотоэлектрические двусторонние $n^{+}-p-p^{+}$-структуры из кремния, выращенного методом Чохральского, с удельным сопротивлением базы $p$-типа $\rho=10 \Omega \cdot \mathrm{cm}, \quad$ концентрацией равновесных дырок $p_{0} \approx 10^{15} \mathrm{~cm}^{-3}$, глубиной диффузионных $n^{+}-p$ и $p-p^{+}$-переходов $d_{n} \approx d_{p} \approx 0.45 \mu \mathrm{m}, \quad$ толщиной $L \approx 200 \mu \mathrm{m}$. Поверхностная концентрация фосфора составляла $N_{\mathrm{P}} \approx 10^{20} \mathrm{~cm}^{-3}$, бора $-N_{\mathrm{B}} \approx 10^{20} \mathrm{~cm}^{-3}$. Образцы площадью $S \approx 1 \mathrm{~cm}^{2}$ были получены при лазерном разделении пластин с помощью твердотельного YAG-лазера в импульсном режиме работы.

Образцы облучались со стороны $n^{+}$-слоя потоком протонов с энергией $E_{p}=40,180 \mathrm{keV}$ и дозой $F_{p}=10^{15} \mathrm{~cm}^{-2}$ при температуре образцов $T_{p}=300$ и $83 \mathrm{~K}$ на имплантере Extrion/Varian: образец № 1 при $E_{p}=180 \mathrm{keV}, T_{p}=83 \mathrm{~K}$; образец № 2 при $E_{p}=40 \mathrm{keV}$, $T_{p}=83 \mathrm{~K}$; образец № 3 при $E_{p}=40 \mathrm{keV}, T_{p}=300 \mathrm{~K}$. Контрольный образец № 4 не облучался.

Импульсные характеристики измерялись с помощью цифрового осциллографа DSOX2022A, работающего в режимах как генератора импульсов напряжения, так и 
мультиметра. Измерения проводились в темноте при температуре $300 \mathrm{~K}$. Исследуемый образец ФЭП через кабель $(R=0.1 \Omega)$ подключался к генератору сигналов. Осциллограф подключался параллельно образцу через высокочастотный шуп $\left(f_{\max }=300 \mathrm{MHz}\right)$. На исследуемый образец с генератора подавались биполярные прямоугольные импульсы напряжения с постоянной амплитудой $U_{0}=10 \mathrm{mV}$ и с частотой $f=200 \mathrm{kHz}$ при длительности импульса $2.5 \cdot 10^{-6} \mathrm{~s}$ либо с частотой $f=1 \mathrm{MHz}$ при длительности импульса $0.5 \cdot 10^{-6}$ s. Зависимость напряжения $U$ от времени измерялась осциллографом. Шаг дискретизации измеряемого сигнала составлял $5 \mathrm{~ns}$ для $f=200 \mathrm{kHz}$ и $2.5 \mathrm{~ns}$ для $f=1 \mathrm{MHz}$. Импульсные характеристики, представленные на рисунке, с достаточной точностью аппроксимируются одноэкспоненциальной зависимостью напряжения от времени для образцов № 2-4 и двухэкспоненциальной зависимостью для образца № 1. Амплитуда прямоугольных импульсов напряжения $U_{0}<k T / q$ выбрана так, чтобы фронт напряжения изменялся симметрично при переключении полярности импульсов и выполнялось условие низкого уровня инжекции неосновных носителей заряда. В масштабе рисунка (части $a$ и $b$ ) зависимости $U(t)$ для образцов № 2-4 близки. На рисунке, $a$ зависимости $U(t)$ для образцов № 2-4 не успевают выйти на насыщение за время длительности импульса, а на рисунке, $b$ все зависимости $U(t)$ не успевают выйти на насыщение за время длительности импульсов.

В результате для образцов № 2-4 найдены близкие значения постоянной времени $\tau$ фронта сигнала, усредненные по периодам импульса напряжения: для образца № $2 \tau=6.6 \cdot 10^{-7} \mathrm{~s}$, для образца № $3 \tau=6.3 \cdot 10^{-7} \mathrm{~s}$, для образца № $4 \tau=6.4 \cdot 10^{-7}$ s. Для образца № 1 найдены два значения: $\tau_{1}=4.2 \cdot 10^{-7} \mathrm{~s}, \tau_{2}=5.5 \cdot 10^{-8} \mathrm{~s}$.

Фронт напряжения при переключении полярности обусловлен процессами изменения неравновесного заряда в $n^{+}$, $p$-областях и ОПЗ $n^{+}-p$-перехода. Поэтому изменение структуры и рекомбинационных свойств ОПЗ влияет на форму фронта сигнала $U(t)$. Найденные значения постоянной времени фронта сигнала много меньше, чем время жизни электронов $\tau_{n}$ в базе, и много больше, чем время жизни дырок $\tau_{p}$ в $n^{+}$-слое.

Протоны с $E_{p}=40 \mathrm{keV}$ создают первичные радиационные дефекты в $n^{+}$-слое на расстоянии $0.41 \mu \mathrm{m}$ от поверхности, их количество в образцах № 2, 3 различается в несколько раз [6], однако значения $\tau$ для этих образцов и образца № 4 близки и, следовательно, не отражают изменения, произошедшие в $n^{+}$-слое. Длительность прямоугольного импульса много меньше $\tau_{n}$, поэтому значения $\tau$ не характеризуют рекомбинационные процессы в базе. Таким образом, фронт сигнала $U(t)$ определяется свойствами ОП3, а значения $\tau$ соответствуют эффективному времени жизни носителей заряда в этой области.

Протоны с $E_{p}=180 \mathrm{keV}$ создают первичные радиационные дефекты на глубине $1.51 \mu \mathrm{m}$ во всей ОПЗ $n^{+}-p$-перехода, пик Брэгга расположен на глубине
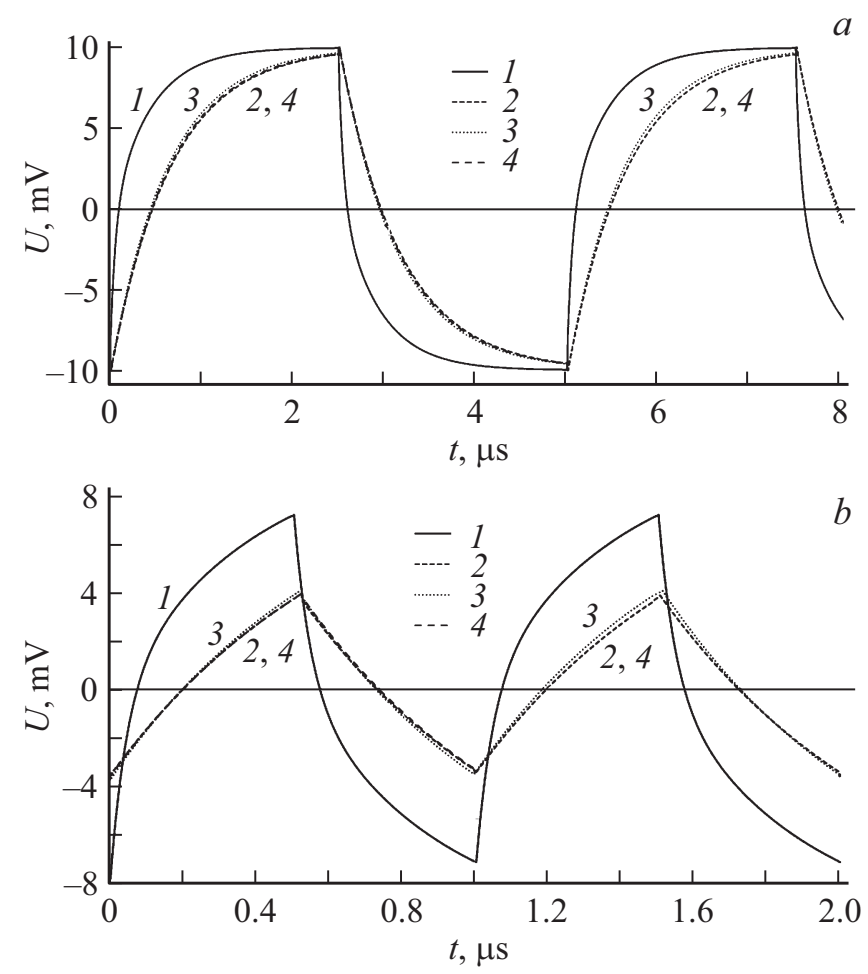

Импульсные характеристики при частоте импульсов напряжения $200 \mathrm{kHz}(a)$ и $1 \mathrm{MHz}(b)$. Номера кривых соответствуют номерам образцов.

$1.48 \mu \mathrm{m}$ [7]. Два значения $\tau_{1}$ и $\tau_{2}$ свидетельствуют о том, что структура ОПЗ образца № 1 изменилась, в ней существуют две области с различными значениями среднего времени жизни. Значение $\tau_{2}$ относится к области с высокой концентрацией радиационных дефектов в окрестности пика Брэгга.

Результаты исследования показывают, что облучение протонами с энергией $180 \mathrm{keV}$ и дозой $10^{15} \mathrm{~cm}^{-2}$ модифицирует свойства ОПЗ $n^{+}-p$-перехода кремниевого ФЭП, снижая значение постоянной времени фронта сигнала напряжения до $5.5 \cdot 10^{-8} \mathrm{~s}$. Такие ФЭП могут использоваться для создания быстродействующих структур с рабочей частотой модуляции $18 \mathrm{MHz}$.

\section{Благодарности}

Авторы благодарят сотрудников ФГБУН „Институт проблем технологии микроэлектроники и особо чистых материалов Российской академии наук Ю.А. Агафонова, В.И. Зиненко за облучение образцов.

\section{Финансирование работы}

Работа выполнена в рамках государственного задания на 2021 г. Федерального исследовательского центра Южного научного центра РАН (номер госрегистрации 01201354240). 


\section{Конфликт интересов}

Авторы заявляют, что у них нет конфликта интересов.

\section{Список литературы}

[1] В.А. Козлов, В.В. Козловский, ФТП, 35 (7), 769 (2001). http://journals.ioffe.ru/articles/viewPDF/38565

[2] C. Bscheid, C.R. Engst, I. Eisele, C. Kutter, Materials, 12 (1), 190 (2019). DOI: 10.3390/ma12010190

[3] И.М. Анфимов, С.П. Кобелева, А.В. Пыльнев, И.В. Щемеров, Д.С. Егоров, С.Ю. Юрчук, Изв. вузов. Материалы электронной техники, 19 (3), 210 (2016). DOI: 10.17073/1609-3577-2016-3-210-216 [Пер. версия: 10.1134/S1063739717080030].

[4] O.G. Koshelev, N.G. Vasiljev, Mod. Electron. Mater., 3 (3), 127 (2017). https://doi.org/10.1016/j.moem.2017.11.002

[5] R. Sam, B. Zouma, F. Zougmoré, Z. Koalaga, M. Zoungrana, I. Zerbo, IOP Conf. Ser.: Mater. Sci. Eng., 29, 012018 (2012). DOI: $10.1088 / 1757-899 \mathrm{X} / 29 / 1 / 012018$

[6] Ю.А. Агафонов, Н.М. Богатов, Л.Р. Григорьян, В.И. Зиненко, А.И. Коваленко, М.С. Коваленко, Ф.А. Колоколов, Поверхность. Рентгеновские, синхротронные и нейтронные исследования, № 10, 86 (2018). DOI: $10.1134 / \mathrm{S} 0207352818110033$

[7] Н.М. Богатов, Л.Р. Григорьян, А.И. Коваленко, М.С. Коваленко, Ф.А. Колоколов, Л.С. Лунин, ФТП, 54 (2), 144 (2020). DOI: 10.21883/FTP.2020.02.48909.9255 